\title{
Range Expansion of Ambrosia artemisiifolia in Europe Is Promoted by Climate Change
}

\author{
Sarah Cunze,, ${ }^{1,2}$ Marion Carmen Leiblein, ${ }^{1}$ and Oliver Tackenberg ${ }^{2}$ \\ ${ }^{1}$ Biodiversity Dynamics and Climate Change, Biodiversity and Climate Research Centre, Senckenberganlage 25, 60325 Frankfurt am \\ Main, Germany \\ ${ }^{2}$ Institute of Ecology, Evolution and Diversity, Goethe University, Max-von-Laue-Straße 13, 60438 Frankfurt am Main, Germany
}

Correspondence should be addressed to Sarah Cunze; scunze@senckenberg.de

Received 8 November 2012; Accepted 2 December 2012

Academic Editors: P. Borges, A. Chappelka, P. Ferrandis, and S. N. Francoeur

Copyright (C) 2013 Sarah Cunze et al. This is an open access article distributed under the Creative Commons Attribution License, which permits unrestricted use, distribution, and reproduction in any medium, provided the original work is properly cited.

\begin{abstract}
Ambrosia artemisiifolia L., native to North America, is a problematic invasive species, because of its highly allergenic pollen. The species is expected to expand its range due to climate change. By means of ecological niche modelling (ENM), we predict habitat suitability for A. artemisiifolia in Europe under current and future climatic conditions. Overall, we compared the performance and results of 16 algorithms commonly applied in ENM. As occurrence records of invasive species may be dominated by sampling bias, we also used data from the native range. To assess the quality of the modelling approaches we assembled a new map of current occurrences of $A$. artemisiifolia in Europe. Our results show that ENM yields a good estimation of the potential range of A. artemisiifolia in Europe only when using the North American data. A strong sampling bias in the European Global Biodiversity Information Facility (GBIF) data for A. artemisiifolia causes unrealistic results. Using the North American data reflects the realized European distribution very well. All models predict an enlargement and a northwards shift of potential range in Central and Northern Europe during the next decades. Climate warming will lead to an increase and northwards shift of A. artemisiifolia in Europe.
\end{abstract}

\section{Introduction}

Ambrosia artemisiifolia L. (common ragweed), native to North America, is considered as one of the most problematic invasive species in Europe (e.g., [1]). The species produces highly allergenic pollen in huge amounts (e.g., [2]). Up to 12\% of the human population suffers from allergy (rhinitis and asthma) to Ambrosia pollen [3]. The medical costs of people with allergies are enormous (e.g., [3]) and will increase in case of a further spread of A. artemisiifolia in Europe.

The invasion of A. artemisiifolia into Europe proceeded in two stages: (1) A. artemisiifolia was inadvertently introduced into Europe in the 19th century and has become a widespread alien species in South-eastern Europe [4]. (2) In the last decade many expanding populations of $A$. artemisiifolia in Central and Northern Europe have been evidenced [5].

Climate change and invasive species are regarded as major threats to biodiversity (e.g., $[6,7]$ ). Invasive species may induce economic problems, particularly in agriculture and forestry [7]. When considering A. artemisiifolia, the main problem is the health risk for human population. Some invasive species may be promoted by climate change (e.g., [8]) due to characteristics that facilitate rapid range shifts (e.g., short time to maturity and low seed mass) and due to their broad climatic tolerances [9]. The introduction of invasive species is often supported by human activities, for example, by affecting natural habitats with global trade, transport, and new transport vectors involved [7, 10]. For the successful establishment of invasive plant species evolutionary factors (e.g., the potential for rapid adaptation to novel environmental conditions) play an important role $[7,11]$. In case of A. artemisiifolia, it is controversially discussed whether this northward spread is mainly caused by climate change or due to an increased import of contaminated seeds and birdseeds [2]. In this study we focus on the effect of climate change on the expansion of $A$. artemisifolia. The elongation of the growing season under climate change may especially promote late flourishing annuals and thus advantage a potential range 
shift northwards. Contamination in traded crops and birdseeds seems to be one of the main vectors for seed dispersal of $A$. artemisiifolia [12]. In Central Europe, A. artemisiifolia has thus also thrived from the increasing import of seeds from South-eastern Europe, where A. artemisiifolia is very common. In addition, the broad ecological amplitude of the species (e.g., $[13,14])$ may promote its invasion success.

Because of the expected spread and the consequent costs involved for public health there is a special interest in locating places where suitable habitat conditions for A. artemisiifolia prevail, in estimating the invasive potential of the species and in predicting the impact of climate change on the geographical range of the species.

Thus the main aim of our study is to assess the impact of the expected climate change on the geographical range of $A$. artemisiifolia in Europe by means of ecological niche modelling (ENM). ENM is an established and successful method to estimate the potential distribution of plant or animal species under current environmental conditions and environmental scenarios (e.g., [15]). Based on the information on current occurrences of the species and the environmental conditions at these locations the species-environmentrelationships are quantified by means of statistical models [16].

ENM has been applied to quantify biological invasions (e.g., [17]). However, there are some difficulties. Considering invasive species, it is especially difficult to distinguish absence due to unsuitable habitat conditions from absence due to dispersal limitation. ENM assumes that the distribution of the species is in equilibrium with the environmental conditions (e.g., [18]), that is, the potential distribution equals the actual distribution. This assumption of equilibrium (e.g., [19]) may often be violated in the case of invasive species within the invaded new range because they might not occupy all suitable habitats due to dispersal limitations.

One way to deal with the potentially violated equilibrium assumption in case of invasive species is to use data from the native range to train the model and then to transfer the species environment relationship to the invaded area (adventive range). This is called transferability in space [20]. So, we used two approaches to model the species-environmentalrelationships for $A$. artemisiifolia. On the one hand we used the European data (occurrence data and environmental data) and on the other hand we used the native range data, that is, the North American data.

As occurrence data we used geo-referenced locations from the Global Biodiversity Information Facility (GBIF) database (http://www.gbif.org/). Offering a vast amount of freely available occurrence data, the GBIF database is potentially a valuable resource for the use in ENM [21] but collection records may suffer from sampling bias.

As a distribution map of $A$. artemisiifolia for all over Europe following standard guidelines is still missing (e.g., [5]) and because of the potential sampling bias in the GBIF data, we also collected independent information on the current distribution of $A$. artemisiifolia from several national distribution maps and databases and collated a new map of the European distribution from these data. This information was used as independent data to evaluate the accuracy of
ENM results. We decided to use these data only for evaluation and not for modelling.

To model the potential European range of $A$. artemisifolia under future climate conditions we took nine different environmental scenarios into account. Comparing these results with the modelled European range under current climate conditions enables the estimation of the invasive potential of $A$. artemisiifolia in Europe and answers the following three questions: (1) In which regions of Europe will the habitat suitability for $A$. artemisiifolia change under a climate warming scenario? (2) Are there on average better conditions in Europe for A. artemisiifolia to occur due to predicted climate warming? (3) How certain are the predictions?

\section{Materials and Methods}

2.1. Environmental Variables. As environmental variables we used climatic variables of current conditions (19502000) derived from the WorldClim global climate database (http:/www.worldclim.org/, [22]). We did not take other environmental variables like land-use into account. Although land-use is an important factor for A. artemisiifolia on a local scale (A. artemisiifolia mainly occurs in ruderal and segetal habitats in Europe) taking land-use data into account would not impact the large scale patterns of the modelling results [23]. In addition, we principally aim to predict the future spread of A. artemisiifolia on the basis of climate change, only.

Some ENM algorithms do not deal well with intercorrelated environmental variables [16]. Therefore we chose a subset of six climatic variables (mean diurnal temperature range, temperature seasonality, mean temperature of the warmest quarter, precipitation seasonality, precipitation of the wettest quarter, precipitation of the driest quarter) among the original 19 available climatic variables which were not strongly intercorrelated within the study region (Spearman correlation coefficient rho $<0.8$ in both, the native and adventive range).

To forecast the potential geographical distribution of $A$. artemisiifolia in Europe under future climate conditions we used the IPCC scenarios A1, A2 and B1 for 2080 [24] and the three Global Circulation Models (GCMs, see Table 2 in Supplementary Appendix 3, available online at http://dx .doi.org/10.1155/2013/610126): the Coupled Global Climate Model CGCM (e.g. [25]), the CSIRO Atmospheric Research Climate Model [26] and the Hadley Centre Coupled Model HadCM3 [27, 28].

We used data from the third IPCC report provided by the International Centre for Tropical Agriculture-CIAT with a spatial resolution of 5 minutes.

2.2. Species Occurrence Data. Georeferenced distribution data (presence only) of $A$. artemisiifolia were retrieved from GBIF on June 15th 2009. Occurrence records of an accuracy of less than one decimal place were not considered. From the native ranges of $A$. artemisiifolia in North America, 2016 presence records were available and from the adventive ranges in Europe 2779 records (see Supplementary Appendix 1 for detailed information on the data providers). 
To evaluate the quality of the modelling results, we randomly split the occurrence data at a ratio of $70: 30$ to obtain two subsets of the data: one for training the model and the other for testing the model's predicted distribution, respectively. In addition, we used independent data on the range of A. artemisiifolia to test the agreement between modelled and observed ranges and to assess a potential bias in the GBIF data. Since a distribution map for all over Europe following standard guidelines was still missing, data from more than 40 national distribution maps and data bases were collated and condensed in a distribution map covering Europe (see Supplementary Appendix 2 for detailed information about the used data sources).

2.3. Study Area and Resolution. The spatial extent of our data ranges from $35^{\circ} \mathrm{N}$ to $79^{\circ} \mathrm{N}$ and from $10^{\circ} \mathrm{W}$ to $70^{\circ} \mathrm{E}$ (Europe), respectively, from $11^{\circ} \mathrm{N}$ to $58^{\circ} \mathrm{N}$ and from $130^{\circ} \mathrm{W}$ to $50^{\circ} \mathrm{W}$ (North America). The spatial resolution for the environmental information is $5^{\prime} \times 5^{\prime}$ which is in accordance with the precision of the coordinates of GBIF occurrence records.

2.4. Ecological Niche Modelling. It has been demonstrated that there is a high variability in model prediction from one algorithm to another (e.g., [29]). For not relying on only one algorithm and being able to assess the uncertainty caused by different approaches we used 16 different algorithms. See Table 1 in Supplementary Appendix 3 for a list of algorithms and where they are implemented. For algorithms that make use of absence data 10,000 pseudo absence points were chosen at random from non-occurrences within the study area.

We applied two approaches to estimate the potential range of A. artemisiifolia in Europe: first, we modelled the species-environment-relationship based on the European dataset - that is, the climatic niche in the invasive range-and projected the climatic niche onto Europe (adventive range approach). Secondly, we projected the species-environmentrelationship developed with the North American datasetthat is, the climatic niche in the native range-onto Europe (cf. [30]) (native range approach).

To choose the best single models we considered the AUC values ("area under the receiver operating characteristic curve", [31]) and the point biserial correlation (COR) between the modelling results and the independent test data [29] two frequently used measures of model performance [32].

To convert the continuous modelling results into binary presence and absence data we took the threshold minimizing the difference between sensitivity and specificity ( $P$ fair) as optimization criteria [33]. Software: ROC/AUC-calculation (http://lec.wzw.tum.de/index.php?id=67\&L=1).

2.5. Consensus Maps. A method to decrease the predictive uncertainty of single-models is to combine the predictions of the best performing algorithms in a consensus map [34]. Marmion et al. [34] suggest calculating the average of the best single-models weighted by their AUC values. The AUC values were calculated by the use of test data of the same range and quality as the trainings data (e.g., native range data)—using
$30 \%$ of the GBIF data chosen at random and not used for training and about ten times as much of pseudo absences, also chosen at random.

We applied the consensus method according to Marmion et al. [34] to modelling results that were standardized in respect to the mean habitat suitability within the full study area of the training datasets. Otherwise, good performing models that do not exhaust the full range of habitat suitability are underweighted in the average despite their high AUC value. Furthermore we modified the weighting by subtracting 0.5 from the AUC. This last modification is appropriate as it cancels the influence of single indiscriminate models (AUC $\approx$ $0.5)$.

Additionally; we displayed the percentage of models predicting presence of $A$. artemisiifolia (based on the binary data). This is another possibility to combine several modelling results in a consensus map.

2.6. Evaluation. To evaluate modelling performance we used independent distribution data for A. artemisiifolia in Europe derived from the newly created distribution map. For each modelling result we calculated AUC and COR (cf. [29]).

\section{Results}

3.1. Current Range. The occurrence data from GBIF (Figure 1(a)) differed remarkably from the range derived from national maps and databases (Figure $1(\mathrm{~b})$ ). The modelling results using the adventive range approach reflect the strong sampling bias in GBIF data (e.g., Figure 1(c)) and are thus not satisfying. Conversely, the native range approach obviously provides a more reliable estimation of the potential distribution of A. artemisiifolia (e.g., Figure 1(d)).

The superior performance of the native range approach becomes evident when considering the AUC values and the correlation (COR) between modelling results and observed distribution (Figure 2). For most algorithms the native range approach yields higher AUC and COR values compared to the adventive range approach.

For further analysis we only used the native range approach and the 10 best performing algorithms. The modelling results for these algorithms and the native range data show AUC values $>0.8$ (which is "excellent" according to Hosmer and Lemeshow [35]), except CTA with an AUC value of 0.76 (which is "acceptable" according to Hosmer and Lemeshow [35]). The COR values range between 0.45 and 0.51 .

The consensus map (weighted by the AUC value and the mean habitat suitability of the single models trained and projected onto North America) under current climatic conditions on Figure 3(a) takes an AUC value of 0.86 and a COR-value of 0.52 (evaluation of the projection onto Europe) - using the independent test data (cf. Figure 1(b)). Compared to the single models these is the largest COR-value and the second largest AUC value (after ANN: AUC = 0.86).

Under current climatic conditions A. artemisiifolia is predicted to occur in north Portugal and parts of France (Rhône Valley, Aquitaine), north and middle Italy as well as 


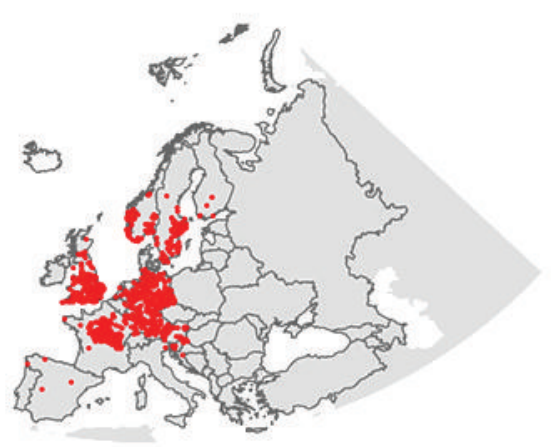

(a)

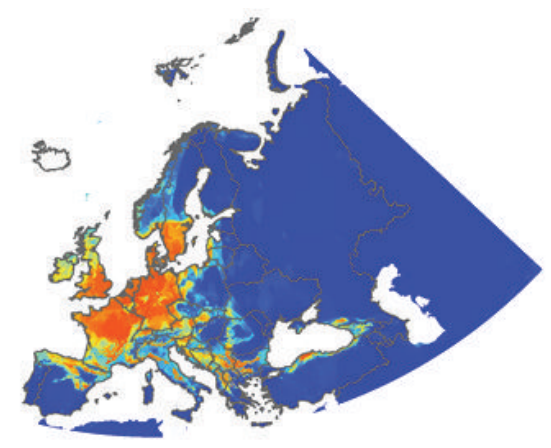

(c)

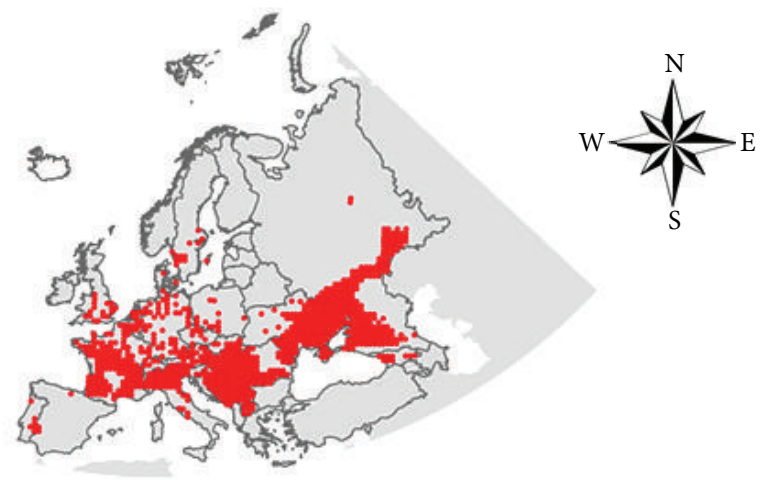

(b)

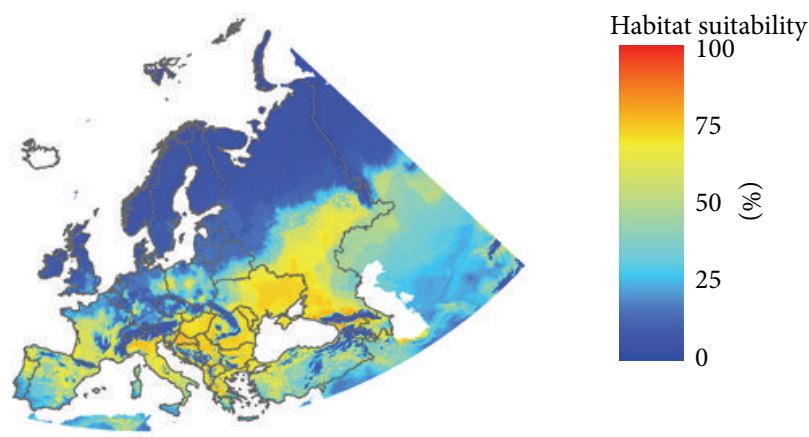

(d)

FIGURE 1: (a) Distribution of the European GBIF records for Ambrosia artemisiifolia ( $N=2048)$. (b) Distribution of Ambrosia artemisiifolia in Europe in $50 \mathrm{~km} \times 50 \mathrm{~km}$ grid cells-based on the information of more than 40 national distribution maps and international data bases (see Supplementary Appendix 2). (c) Modelled habitat suitability of Ambrosia artemisiifolia in Europe under current climatic conditions based on the European data (adventive range approach). Warmer colours show areas with better predicted conditions. Algorithm: GBM. (d) Modelled habitat suitability of Ambrosia artemisiifolia in Europe under current climatic conditions based on the North American data (native range approach). Warmer colours show areas with better predicted conditions. Algorithm: GBM. Projection: Europe Albers Equal Area Conic.

TABLE 1: Area and coordinates of the centre of the area predicted as suitable for Ambrosia artemisiifolia in the consensus maps in Figure 3.

\begin{tabular}{lccc}
\hline & Area $\left(10^{6} \mathrm{~km}^{2}\right)$ & Longitude centre $\left(^{\circ}\right)$ & Latitude centre $\left(^{\circ}\right)$ \\
\hline Consensus map for current conditions (1950-2000) & 3.47 & 27.82 & 45.34 \\
Consensus map for 2080 (B2) & 7.08 & 31.16 & 51.31 \\
Consensus map for 2080 (A1) & 7.10 & 33.01 & 52.56 \\
Consensus map for 2080 (A2) & 7.08 & 32.96 & 53.35 \\
\hline
\end{tabular}

in South-eastern Europe (Hungary, Slovenia, Croatia, Serbia, Albania, south-western Russia, the east of Ukraine, parts of Romania, Montenegro, Bosnia and Herzegovina, Greece) according to the consensus map (Figure 3(a)). In these areas there is also a high consistency of the binary single model results in predicting presence of $A$. artemisiifolia (red and orange areas in Figure 4(a) in Supplementary Appendix 3). In Northern Europe the single models agree in predicting the absence of $A$. artemisiifolia.

3.2. Predicted Range Shifts. The consensus maps for future conditions (Figures 3(b)-3(g)) predict a north-eastwards range shift and a doubling of the surface area predicted as suitable for $A$. artemisiifolia (Table 1). Regarding the predicted shift and the predicted enlargement of the range there are no great differences between the modelling results of the three IPCC scenarios B2, A1, and A2. Nor is there a high variability due to the three considered GCMs. The variability in modelling results is mainly caused by algorithms (see Figure 6 in Supplementary Appendix 3), despite the fact that we only considered the ten best algorithms.

A high uncertainty in modelling the potential range under current climatic conditions prevails in Spain, northern France, Benelux, Germany, Poland, Southern Italy, parts of Russia (in the east of the Caspian Sea), and Turkey (see Figure 5(a) in Supplementary Appendix 3). Considering the potential future distribution of $A$. artemisiifolia, there is a high uncertainty in modelling results in the south-east of the study area and north of the predicted range (Figures 5(b)5(d) in the Supplementary Appendix 3). The outcome of 


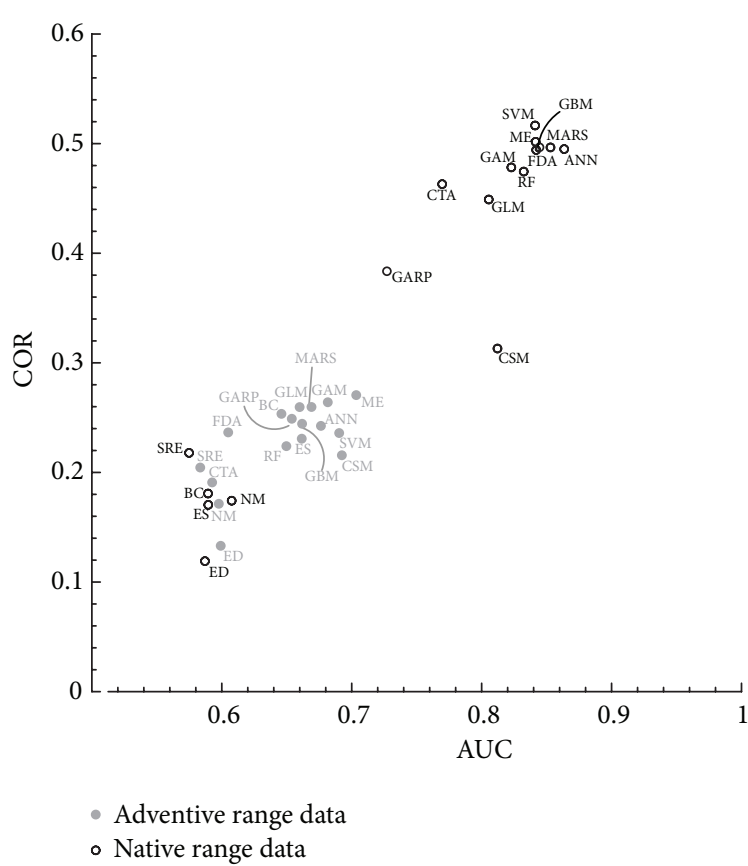

FIgURE 2: Scatterplot of the AUC value and the correlation (COR) between modelling results and observed presence-absence data using independent test data, derived from the distribution map (Figure 1(b)) (ANN-Artificial Neural Networks, BC-Bioclim, CSM-Climate Space Model, CTA-Classification Tree Analysis, ED-Environmental Distance, ES-Envelope score, GARPGenetic Algorithm for Rule, GAM-Generalized Additive Models, GBM-Generalized Boosted Models, GLM-Generalized Linear Models, MARS-Multivariate adaptive regression splines, MEMAXENT, MDA-Mixture Discriminant Analysis, RF-Random Forests, SRE-Surface Range Envelope, SVM-Support Vector Machines).

the high agreement of the models in predicting absence in Northern Europe is the relatively low modelling uncertainty (standard deviation of the modelling results) in this area.

\section{Discussion}

A. artemisiifolia is predicted to shift north-eastwards and to enlarge its potential range in Europe due to climate change. Hence, $A$. artemisiifolia is promoted by climate warming in Europe resulting in a high invasive potential in wide parts of Europe. Using ENM we are able to predict potentially endangered regions on a big scale reliably. Forecasting the potential spread of a strongly allergenic neophyte like $A$. artemisiifolia may be a helpful tool for developing protective measures (e.g., [36]) such as monitoring and eradication in the threatened areas. Counteracting measures must take place in endangered areas where A. artemisiifolia is not established yet.

Modelling the potential distribution of invasive species by means of ENM faces special challenges because of the violated assumption of equilibrium within the adventive range and because of unreliable absence data due to potential dispersal limitation. In case of $A$. artemisiifolia the main problem is the sampling bias in European GBIF data. Using the native range approach we overcame these problems.

To predict the potential range of $A$. artemisiifolia the native range approach performs much better than the adventive range approach. Although the native range approach incorporates no information about the European distribution in the modelling process the modelled niche projected onto Europe reflects the observed distribution well. We presume that native range data outperforms adventive range data also for other invasive species, where the latter is often difficult to obtain (e.g., [37]).

4.1. Why Did We Not Use the Evaluation Map for Modelling? Our evaluation using independent occurrence data has shown that the native range approach yields reliable results under current climatic conditions and can thus be projected to future. ENM based on the newly created map data would probably be more convenient to predict future distribution of A. artemisiifolia in Europe. But collecting occurrence data from several national sources is very time consuming. In contrast, the GBIF data from the native range are for many species easy available and at least in case of A. artemisiifolia obviously reliable. Furthermore we want to point out the need of independent data for evaluation.

An additional advantage of the native range approach is that the modelled niche (proved to be probable according to our evaluation) can be projected onto other areas (e.g., Asia or Australia) to estimate the invasive potential of $A$. artemisiifolia there. Data from the native range are probably easier to use and are not as serious constrained by dispersal limitation as data from the adventive range may be.

4.2. Why Does the First Approach Fail? The bad performance of the adventive range approach may be ascribed mainly to a serious sampling bias in European GBIF data for A. artemisiffolia. Sampling bias means that the probability of being recorded is not equal for all individuals of the species within the study area. Thus, the European GBIF data for A. artemisiifolia do not adequately reflect the actual distribution. For example, there are no GBIF occurrence records for Hungary, the Rhône Valley (France) or the Po Valley (Italy) (Figure 1(a)). According to Makra et al. [38], however, these are the three main regions invaded by $A$. artemisiifolia in Europe. This is also confirmed by pollen maps (http://www.polleninfo.org/).

In contrast to the underrepresentation of records in the regions where $A$. artemisiifolia is said to be very common, almost every occurrence of $A$. artemisiifolia in Germany and Northern Europe is reported to GBIF due to the high public interest in these countries, regardless whether these occurrences are established populations or only single vegetative individuals that may not be able to reproduce successfully but stay non-naturalized instead. Seeds of $A$. artemisiifolia introduced, for example, by contaminated birdseeds may surely be able to germinate in Scandinavia since the species has the ability to germinate under a wide temperature range including also very low temperatures [13]. To establish stable populations, however, annual species have to fulfil their life 


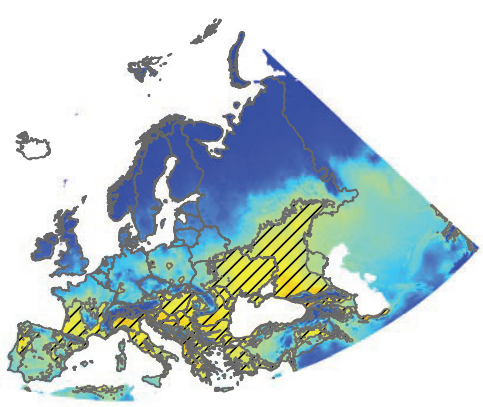

(a) Today (1950-2000)

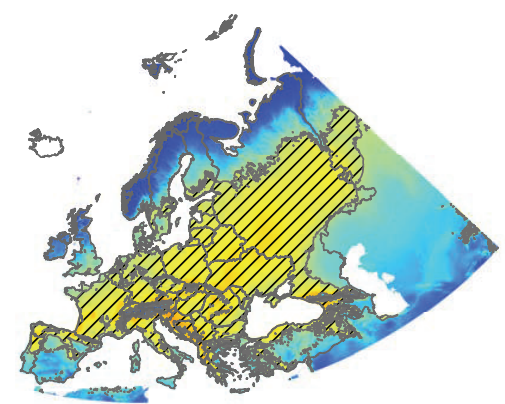

(b) 2080 B2

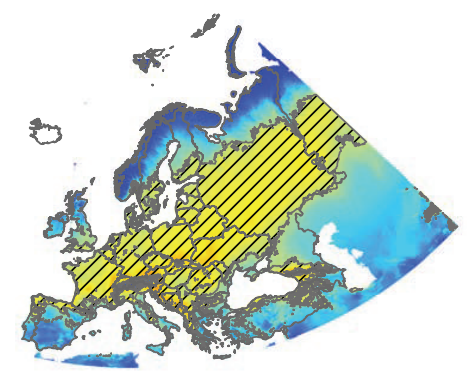

(d) $2080 \mathrm{~A} 1$

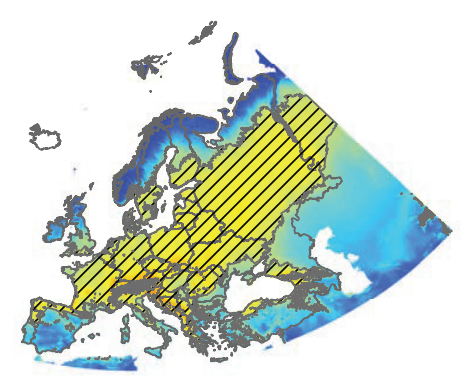

(f) $2080 \mathrm{~A} 2$

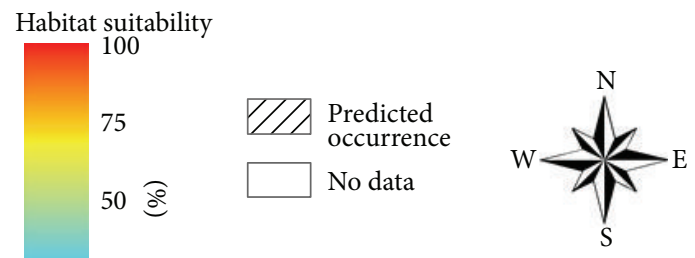

25
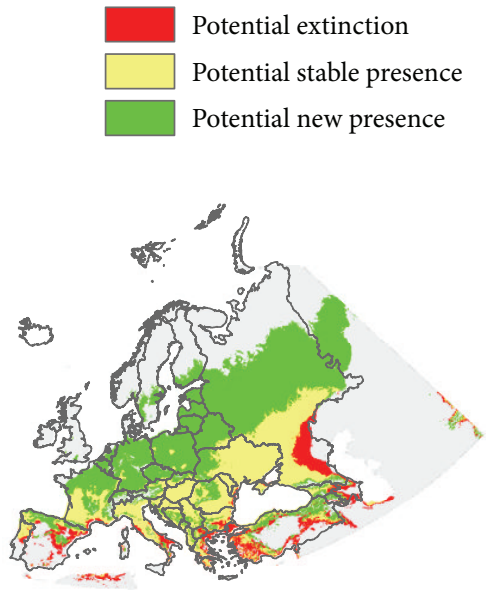

(c)

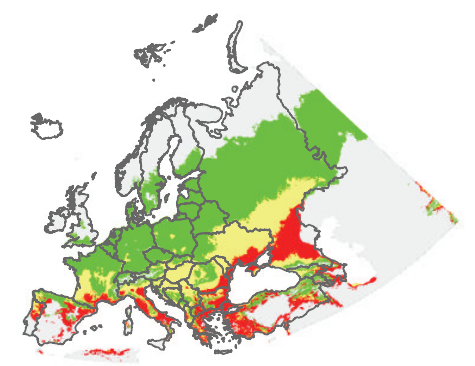

(e)

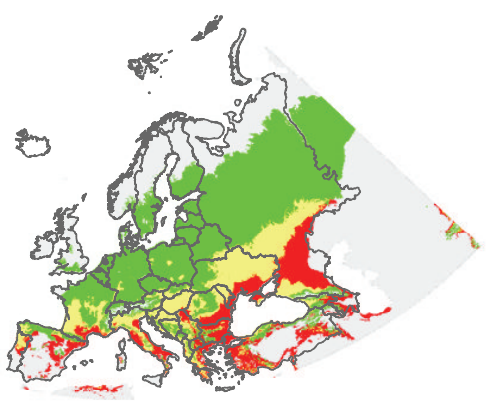

(g)

FIGURE 3: Predicted habitat suitability for Ambrosia artemisiifolia (a) under current climatic conditions (b) and (c) for 2080 considering the B2 IPCC Scenario (d) and (e) for 2080 considering the A1 IPCC Scenario and (f) and (g) for 2080 considering the A2 IPCC Scenario. Shown are the modelling results based on the North American GBIF data. Consensus maps of the ten "best" algorithms (ANN, CTA, FDA, GAM, GBM, GLM, MARS, ME, RF, SVM) weighted by their AUC values. For the future Scenarios the consensus maps include the modelling results of three different GCMs (CCCMA, CSIRO, HADCM3). The threshold for the binary results ( $P$ fair $=0.645-$ minimizing the difference between sensitivity and specificity) is based on the evaluation of the consensus map of the ten "best" algorithms projected on North America using the GBIF test data (30\% of the North American GBIF records for A. artemisiifolia chosen at random and not used for training). Projection: Europe Albers Equal Area Conic. 
cycle to produce mature seeds. A. artemisiifolia on average needs an accumulated temperature sum of $1400^{\circ} \mathrm{C}$ (own data, unpublished) to achieve this phenological phase. This amount of accumulated temperature, however, occurs in Northern Europe under actual climatic conditions only in single extremely warm years. Therefore, in general A. artemisiifolia is still ephemeral in Scandinavia with few exceptions, but this may change in Southern Scandinavia due to global warming as our results suggest. The obvious overrepresentation of $A$. artemisiifolia in Central and Northern Europe in the GBIF database differs remarkably from the common assumption that invasive species may be more likely to be underestimated in databases at their range margins.

4.3. The Native Range Approach Yields Satisfying Results. The better performance of the native range approach may be primarily founded in the lack of dispersal limitation of A. artemisiifolia within the native range which means that the species is better in equilibrium with its environment compared to the adventive range. Furthermore there might be a more consistent mapping of A. artemisiifolia in North America because of missing national frontiers. Modelling uncertainty (standard deviation of the single model results, Figure 3 in Supplementary Appendix 3) is rather low in the areas predicted as suitable (e.g., binary consensus map, Figure 4 in Supplementary Appendix 3). The high uncertainty in the area around the Caspian Sea can be traced back to the different results of a few single models (e.g., MARS versus GAM, see Figure 3 in Supplementary Appendix 3).

Readers familiar with the distribution of A. artemisiifolia in Europe will notice some differences between modelled and observed distribution. In north-western Europe (e.g., France and Germany) the potential distribution for A. artemisiifolia may be underestimated. One reason for this may be that the climatic variables used for modelling reflect the mean climatic conditions for the years 1950 to 2000. Global warming, however, has already taken place. The modelling results using these data estimate the potential distribution under these past climatic conditions and the potential distribution under current (warmer) conditions may thus be underestimated. Regarding the modelling result (consensus map) for the native range (see Figure 1(b) in Supplementary Appendix 3) we notice that the predicted range only covers the densely clustered area in the east. Scattered records in the west are not included. The modelling result only reflects the main range and is thus a conservative estimation of the native range. Hence, the projection onto Europe also yields a conservative estimation.

In contrast to the rather low habitat suitability predicted for north-western Europe, the modelling results may overestimate the occurrence of $A$. artemisiifolia in the Mediterranean region. A possible reason for Ambrosia's absence in the Mediterranean region despite of predicted habitat suitability may be that North American populations adapted to Mediterranean climatic conditions did not reach the adventive range (Europe) yet. As the modelled speciesenvironment-relationship is based on all (native range) populations which have evolved throughout time the modelled niche may be wider than the climatic niche of these populations occurring in Europe. In some cases the realized niches of a species may vary between native and introduced ranges [39]. This may complicate the cross-continental transfer of models [40]. But altogether in the case of A. artemisiifolia the modelling results using the native range approach represent the observed distribution pattern of A. artemisiifolia in Europe well.

4.4. How Will Climate Change Affect the Range of Ambrosia in Europe? The high AUC values for the "ten best performing" algorithms and the consensus maps using independent data for evaluation justify the projection onto the future climate conditions. The predicted enlargement of the area predicted as suitable for A. artemisiifolia under future climatic conditions and the predicted range shift north-eastwards meets common expectations [15]. This corroborates the assumption that the invasive potential of $A$. artemisiifolia in Central and Northern Europe is promoted by climate warming. Essl et al. [41] state that global warming will enhance the invasive success of A. artemisiifolia in Austria based on the close relation of the distribution of $A$. artemisiifolia to the temperature in a generalized linear model. We confirm this trend for wide areas of Europe and corroborate the assumption that A. artemisiifolia thrived from climate warming by applying several algorithms.

We therefore conclude that huge areas (especially North France, Germany, Benelux, Czech Republic, Poland, the Baltic States, Belarus, and wide parts of Russia) are potentially endangered by an invasion of this species, especially under climate change. Since A. artemisiifolia is mainly supported and distributed through human activities [42] the species may cover long distances in a short time span. It is also stated that several introduction events still take place in different European countries. Regarding the likely extension of the species range in Europe that our results suggest we will encounter serious threats for human health. Already now there are costs of several million Euros per year in different countries due to $A$. artemisiifolia allergies (e.g., 110 Mio $€$ /year in Hungary, [43]). In view of the harms done in terms of public health and of its high costs induced in consequence of an increasingly invasive potential, there is a strong need of control measures to minimize further spread of this species.

\section{Conclusions}

Global warming will promote the further spread and the invasive potential of A. artemisiifolia in Europe according to our modelling results. Therefore, we strongly encourage timely international management strategies. Generally, containment measures against invasive species are only efficient in the beginning of the spread [5]. After their establishment measures may become extremely expensive and increasingly unsuccessful [44]. Monitoring and management measures are strongly and timely needed, especially in regions newly endangered due to climate change. For a successful management, this may be combined with the method of ENM in 
order to better understand the ecological requirements and range dynamics of the species.

\section{Acknowledgments}

The present study was conducted at the Biodiversity and Climate Research Centre (BiK-F), Frankfurt a.M., and funded by the research funding programme "LOEWE-LandesOffensive zur Entwicklung Wissenschaftlich-ökonomischer Exzellenz" of Hesse's Ministry of Higher Education, Research, and the Arts, as well as by the DFG (TA 311/3). The authors thank Konstantin König and Jaime García Márquez for their valuable help and comments during the development of this research.

\section{References}

[1] T. C. G. Rich, "Ragweeds (Ambrosia L.) in Britain," GRANA, vol. 33, no. 1, pp. 38-43, 1994.

[2] G. Vogl, M. Smolik, L. M. Stadler et al., "Modelling the spread of ragweed: effects of habitat, climate change and diffusion," European Physical Journal, vol. 161, no. 1, pp. 167-173, 2008.

[3] P. Taramarcaz, C. Lambelet, B. Clot, C. Keimer, and C. Hauser, "Ragweed (Ambrosia) progression and its health risks: will Switzerland resist this invasion?" Swiss Medical Weekly, vol. 135, no. 37-38, pp. 538-548, 2005.

[4] B. Chauvel, F. Dessaint, C. Cardinal-Legrand, and F. Bretagnolle, "The historical spread of Ambrosia artemisiifolia L. in France from herbarium records," Journal of Biogeography, vol. 33, no. 4, pp. 665-673, 2006.

[5] B. Alberternst, S. Nawrath, and F. Klingenstein, "Biologie, Verbreitung und Einschleppungswege von Ambrosia artemisiifolia in Deutschland und Bewertung aus Naturschutzsicht, Biology, distribution and pathways of introduction of Ambrosia artemisiifolia in Germany and assessment from a nature conservation point of view," Nachrichtenblatt des Deutschen Pflanzenschutzdienstes, vol. 58, pp. 1-7, 2006.

[6] S. Pompe, J. Hanspach, F. Badeck, S. Klotz, W. Thuiller, and I. Kühn, "Climate and land use change impacts on plant distributions in Germany," Ecology Letters, vol. 4, pp. 564-567, 2008.

[7] O. Bossdorf, H. Auge, L. Lafuma, W. E. Rogers, E. Siemann, and D. Prati, "Phenotypic and genetic differentiation between native and introduced plant populations," Oecologia, vol. 144, no. 1, pp. 1-11, 2005.

[8] W. Thuiller, D. M. Richardson, and G. F. Midgley, "Will climate change promote alien invasions?" in Biological Invasions, W. Nentwig, Ed., vol. 193, pp. 197-211, Springer, Berlin, Germany, 2007.

[9] J. J. Hellmann, J. E. Byers, B. G. Bierwagen, and J. S. Dukes, "Five potential consequences of climate change for invasive species," Conservation Biology, vol. 22, no. 3, pp. 534-543, 2008.

[10] V. Hermoso, M. Clavero, F. Blanco-Garrido, and J. Prenda, "Invasive species and habitat degradation in Iberian streams: an analysis of their role in freshwater fish diversity loss," Ecological Applications, vol. 21, no. 1, pp. 175-188, 2011.

[11] P. J. Prentis, J. R. U. Wilson, E. E. Dormontt, D. M. Richardson, and A. J. Lowe, "Adaptive evolution in invasive species," Trends in Plant Science, vol. 13, no. 6, pp. 288-294, 2008.
[12] G. Schrader, "Risikoanalyse von gebietsfremden Pflanzen? Das neue Konzept der EPPO," Gesunde Pflanzen, vol. 56, no. 3, pp. 75-79, 2004.

[13] P. Steinbauer and B. Grigsby, "Interaction of temperature, light, and moistening agent in the germination of weed seeds," Weeds, vol. 5, pp. 175-182, 1957.

[14] M. C. Leiblein and R. Lösch, "Biomass development and $\mathrm{CO}_{2}$ gas exchange of Ambrosia artemisiifolia L. under different soil moisture conditions," Flora, vol. 206, no. 5, pp. 511-516, 2011.

[15] E. Martínez-Meyer, "Climate change and biodiversity: some considerations in forecasting shifts in species' potential distribution," Biodiversity Informatics, vol. 2, pp. 42-55, 2005.

[16] A. Guisan and W. Thuiller, "Predicting species distribution: offering more than simple habitat models," Ecology Letters, vol. 8, no. 9, pp. 993-1009, 2005.

[17] W. Thuiller, D. M. Richardson, P. Pyssek, G. F. Midgley, G. O. Hughes, and M. Rouget, "Niche-based modelling as a tool for predicting the risk of alien plant invasions at a global scale," Global Change Biology, vol. 11, no. 12, pp. 2234-2250, 2005.

[18] A. Jiménez-Valverde, J. M. Lobo, and J. Hortal, "Not as good as they seem: the importance of concepts in species distribution modelling," Diversity and Distributions, vol. 14, no. 6, pp. 885$890,2008$.

[19] M. P. Austin, "Spatial prediction of species distribution: an interface between ecological theory and statistical modelling," Ecological Modelling, vol. 157, no. 2-3, pp. 101-118, 2002.

[20] C. F. Randin et al., "Are niche-based species distribution models transferable in space?" Journal of Biogeography, vol. 33, pp. 1689-1703, 2006.

[21] P. Flemons, R. Guralnick, J. Krieger, A. Ranipeta, and D. Neufeld, "A web-based GIS tool for exploring the world's biodiversity: the Global Biodiversity Information Facility Mapping and Analysis Portal Application (GBIF-MAPA)," Ecological Informatics, vol. 2, no. 1, pp. 49-60, 2007.

[22] R. J. Hijmans, S. E. Cameron, J. L. Parra, P. G. Jones, and A. Jarvis, "Very high resolution interpolated climate surfaces for global land areas," International Journal of Climatology, vol. 25, no. 15, pp. 1965-1978, 2005.

[23] R. G. Pearson and T. P. Dawson, "Predicting the impacts of climate change on the distribution of species: are bioclimate envelope models useful?" Global Ecology and Biogeography, vol. 12, no. 5, pp. 361-371, 2003.

[24] IPCC, Climate Change 2007: the Physical Science Basis. Contribution of Working Group I to the Fourth Assessment, Report of the Intergovernmental Panel on Climate Change, Cambridge University Press, New York, NY, USA, 2007.

[25] G. M. Flato, G. J. Boer, W. G. Lee et al., “The Canadian centre for climate modelling and analysis global coupled model and its climate," Climate Dynamics, vol. 16, no. 6, pp. 451-467, 2000.

[26] A. C. Hirst, H. B. Gordon, and S. P. O’Farrell, “Global warming in a coupled climate model including oceanic eddy-induced advection," Geophysical Research Letters, vol. 23, no. 23, pp. 3361-3364, 1996.

[27] C. Gordon, C. Cooper, C. A. Senior et al., "The simulation of SST, sea ice extents and ocean heat transports in a version of the Hadley Centre coupled model without flux adjustments," Climate Dynamics, vol. 16, no. 2-3, pp. 147-168, 2000.

[28] V. D. Pope, M. L. Gallani, P. R. Rowntree, and R. A. Stratton, "The impact of new physical parametrizations in the Hadley Centre climate model: HadAM3," Climate Dynamics, vol. 16, no. 2-3, pp. 123-146, 2000. 
[29] J. Elith, C. H. Graham, R. P. Anderson et al., "Novel methods improve prediction of species' distributions from occurrence data," Ecography, vol. 29, pp. 129-151, 2006.

[30] A. T. Peterson, M. Papes, and D. A. Kluza, "Predicting the potential invasive distributions of four alien plant species in North America," Weed Science, vol. 51, no. 6, pp. 863-868, 2003.

[31] A. H. Fielding and J. F. Bell, "A review of methods for the assessment of prediction errors in conservation presence/absence models," Environmental Conservation, vol. 24, no. 1, pp. 38-49, 1997.

[32] J. Elith and J. R. Leathwick, "Species distribution models: ecological explanation and prediction across space and time," Annual Review of Ecology, Evolution, and Systematics, vol. 40, no. 1, pp. 677-697, 2009.

[33] B. Schröder and O. Richter, "Are habitat models transferable in space and time?" Zeitschrift für Ökologie und Naturschutz, vol. 8, no. 4, pp. 195-205, 1999.

[34] M. Marmion, M. Parviainen, M. Luoto, R. K. Heikkinen, and W. Thuiller, "Evaluation of consensus methods in predictive species distribution modelling," Diversity and Distributions, vol. 15, no. 1, pp. 59-69, 2009.

[35] D. W. Hosmer and S. Lemeshow, Applied Logistic Regression, John Wiley \& Sons, New York, NY, USA, 2000.

[36] J. S. Clark, "Ecological forecasts: an emerging imperative," Science, vol. 293, no. 5530, pp. 657-660, 2001.

[37] C. Perrings, K. Dehnen-Schmutz, J. Touza, and M. Williamson, "How to manage biological invasions under globalization," Trends in Ecology and Evolution, vol. 20, no. 5, pp. 212-215, 2005.

[38] L. Makra, M. Juhász, R. Béczi, and E. Borsos, "The history and impacts of airborne Ambrosia (Asteraceae) pollen in Hungary," GRANA, vol. 44, no. 1, pp. 57-64, 2005.

[39] O. Broennimann, U. A. Treier, H. Müller-Schärer, W. Thuiller, A. T. Peterson, and A. Guisan, "Evidence of climatic niche shift during biological invasion," Ecology Letters, vol. 10, no. 8, pp. 701-709, 2007.

[40] S. Dullinger, I. Kleinbauer, J. Peterseil, M. Smolik, and F. Essl, "Niche based distribution modelling of an invasive alien plant: effects of population status, propagule pressure and invasion history," Biological Invasions, vol. 11, no. 10, pp. 2401-2414, 2009.

[41] F. Essl, S. Dullinger, and I. Kleinbauer, "Changes in the spatiotemporal patterns and habitat preferences of Ambrosia artemisiifolia during its invasion of Austria," Preslia, vol. 81, no. 2, pp. 119-133, 2009.

[42] G. Kazinczi, I. Béres, R. Novák, K. Bíró, and Z. Pathy, "Common ragweed (Ambrosia artemisiifolia L.): a review with special regards to the results in Hungary. Taxonomy, origin and distribution, morphology, life cycle and reproduction strategy," Herbologia, vol. 9, pp. 55-91, 2008.

[43] Á. Tóth, P. Z. Hoffmanné, and L. Szentey, “Ambrosia situation in Hungary in 2003. Difficulties of pollen reduction in the air," in Proceedings of the 10th Plant Protection Days, Budapest, Hungary, 2004.

[44] D. Pimentel, R. Zuniga, and D. Morrison, "Update on the environmental and economic costs associated with alien-invasive species in the United States," Ecological Economics, vol. 52, no. 3, pp. 273-288, 2005. 

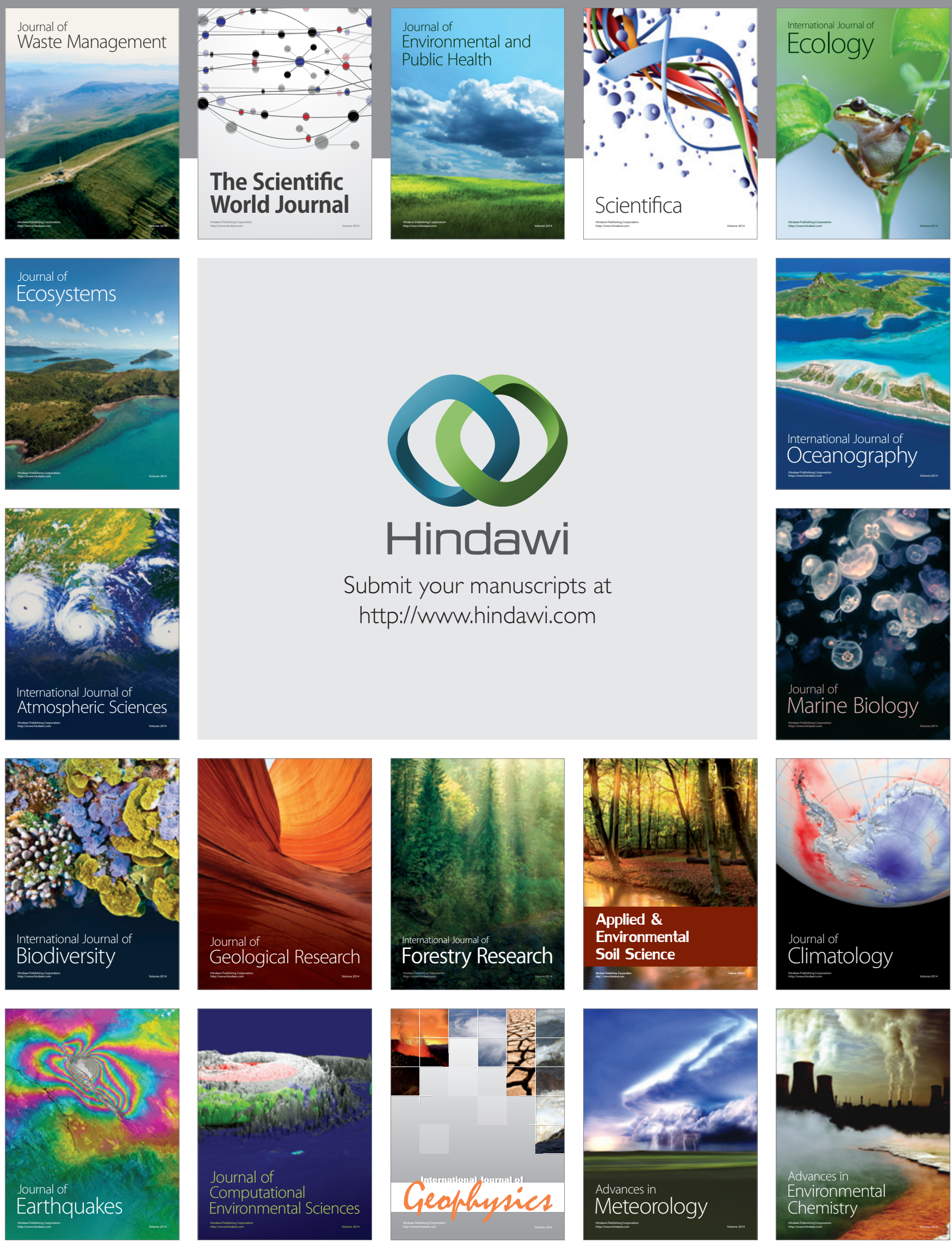